\title{
PADUAN VARIASI PUTARAN 0, 250, 550 RPM CENTRIFUGAL CASTING SIFAT FATIK PADUAN A 356 UNTUK VELG SEPEDA MOTOR
}

\author{
M. Abdus Shomad \\ Jurusan Teknik Mesin, Politeknik, Universitas Muhammadiyah Yogyakarta \\ Jl. Lingkar Selatan, Kasihan, Bantul, Yogyakarta, 55183 \\ E-mail : abdusshomad@umy.ac.id
}

\begin{abstract}
The destination of this research was to determine the effect of rotational speed on the characteristics of fatigue in centrifugal casting alloy A356 aluminum alloy two-wheeled vehicle with a low round and 350 RPM and 550 RPM middle rounds. The casting in this research using a centrifugal casting method. The material used is a cast aluminum alloy A356. Variations rounds used in centrifugal casting is 350 and $550 \mathrm{RPM}$. Casting process carried out by pre-heating the mold $2500^{\circ} \mathrm{C}, 7500^{\circ} \mathrm{C}$ casting temperature and with the addition of titanium boron grain refiner 12:08\%. Results foundry then made specimen for rotary bending fatigue test in accordance with JIS Z 2274 standard 1.

The examination has been done is the rotary bending fatigue test. The examination results showed that the wheels with a round O RPM produces a voltage amplitude relationship with the number of cycles $\sigma a=350$ RPM rotation have a relationship with the voltage amplitude and at 550 RPM rotation have a relationship with the voltage amplitude.
\end{abstract}

Keywords : A356, Centrifugal Casting, Fatigue, Rotation Speed Variation, Stress Amplitude, Cyclic Stress.

\section{PENDAHULUAN}

Menurut data dari AISI (Asosiasi Industri Sepeda Motor Indonesia) tahun 2013 produksi sepeda motor total mencapai 1.970. 823 unit,. Produk otomotif yang saat ini banyak permintaan dari konsumen yaitu Velg kendaraan roda dua. Velg adalah salah satu komponen sepeda motor yang dalam kerjanya mengalami pembeban yang berulang (beban dinamis). Pembebanan berulang inilah yang menyebabkan kegagalan material (fatik). Saat ini diperkirakan kegagalan karena kelelahan kurang lebih $90 \%$ dari seluruh kegagalan yang disebabkan oleh hal - hal berhubungan pembebanan berulang (ASM Vol. 19, 1997:1099). Centrifugal casting merupakan metode pengecoran dimana logam cair membeku di dalam cetakan yang berputar. Centrifugal casting lebih baik dari pada gravity casting (Joshi, 2010).

Proses pengecoran dengan teknik centrifugal casting adalah salah satu metode yang dapat digunakan untuk menghasilkan komponen - komponen yang berbentuk silindris, seperti poros pejal atau berlubang, cylinder liners, bearing bushes, dan lain lain (Bambang, 2010). Proses pengecoran dengan teknik centrifugal casting ini dapat meningkatkan sifat mekanis dari produk cor yang dihasilkan. Demikian juga, dengan paduan aluminium A356 yang akan digunakan sebagai bahan dasar dalam penelitian ini, diharapkan dapat meningkatkan sifat mekanis dan mengurangi porositas dari produk yang akan dihasilkan. Penelitian yang berkaitan dengan teknik centrifugal casting maupun yang berkaitan dengan paduan aluminium A356 masih perlu dilakukan.

Chirita, (2008) membuat perbandingan sifat mekanis spesimen yang diperoleh dari hasil pengecoran dengan teknik centrifugal casting dan gravity casting dari tiga jenis paduan Al - Si yang berbeda. Paduan yang digunakan adalah hypoeutectic alloyeutectic alloy, dan hypereutectic alloy. Hasil pengamatan menunujukkan bahwa efek centrifugal casting untuk beberapa paduan tersebut dapat meningkatkan rupture strength kira - kira50\%, dan rupture strain sekitar 300\%, Young Modulus naik sekitar 
$20 \%$ dibandingkan dengan teknik gravity casting.

Tjitro, dkk (2004) menyatakan struktur mikro hasil centrifugal casting berbentuk equiaxed dan columnar dengan orientasi kemiringan sesuai dengan arah putaran mesin. Sabatino, et al, (2006) menyatakan bahwa temperatur cetakan yang lebih tinggi menghasilkan fluiditas yang baik.

Kandungan $M g$ dapat memberikan pengaruh yang sangat siginifikan terhadap perilaku natural dan artificial aging paduan aluminium, yaitu diperolehnya indek kualitas optimum menggunakan short solution heat treatment selama 1 jam pad atemperatur $540^{\circ} \mathrm{C}$ (Moller, et, al 2007). Maliwemu (2012) menyatakan bahwa putaran centrifugal casting sangat mempengaruhi karakteristik perambatan retak fatik. Syukron, (2011) menyatakan spesimen dengan perlakuan panas T6 mempunyai ketahanan rambat retak fatik lebih baik dibanding spesimen tanpa perlakuan panas T6.

\section{METODE PENELITIAN}

Peralatan utama yang digunakan dalam penelitian ini, antara lain: alat pengecoran dengan sistem centrifugal casting dan alat uji rotary bending, seperti tersaji pada gambar 1 dan 2. Material yang digunakan pada penelitian ini yaitu alumunium A.356 dengan kandungan komposisi $\mathrm{Al} \mathrm{93,22 \% ,Si}$ 5,69\%, Mg 0,18\%, Mn 0,020\%, Cu>0,050.

Tahapan dalam penelitian ini yaitu melakukan proses pengecoran dengan melakukan langkah uji coba dengan memutar cetakan sesuai dengan variasi putaran yang telah ditentukan. Pada tahap awal peneliti melakukan uji coba terhadap cara kerja sistem cenrifugal casting. Tersaji pada gambar 1 cetakan centrifugal casting. Uji coba untuk mengetahui mekanisme sisitem cetrifugal casting yaitu, kemudahan dalam membuka dan menutup cetakan saat kondisi panas, fungsi ejektor untuk mengeluarkan hasil coran dari cetakan, serta berfungsi atau tidaknya laluan udara agar tidak ada udara terjebak.
Pada tahap berikutnya adalah melakukan pemanasan awal (pre-heating) pada cetakan dengan suhu $250^{\circ} \mathrm{C}$. Pada pre-heating menggunakan Liquefied Petroleum Gas (LPG), dengan menempatkan burner diantara cetakan atas dan bawah sampai temperatur cetakan mencapai $250^{\circ} \mathrm{C}$, seperti tersaji pada gambar 1. Setelah terkondisikan suhu cetakan $250^{\circ} \mathrm{C}$, selanjutnya dilakukan proses peleburan paduan aluminium A356 yang akan dituangkan pada cetakan dengan suhu tuang $750^{\circ} \mathrm{C}$. Proses selanjutnya cetakan diputar dengan variasi mulai 0 , 350,550 RPM. Setelah cetakan dingin, velg kendaraan roda dua yang dihasilkan seperti tersaji dalam gambar 3, selanjutnya dipotong - potong dibuat spesimen uji. Proses berikutnya yaitu untuk pembuatan benda uji rotari banding dengan standar - standar JIS Z 2274 No.1.

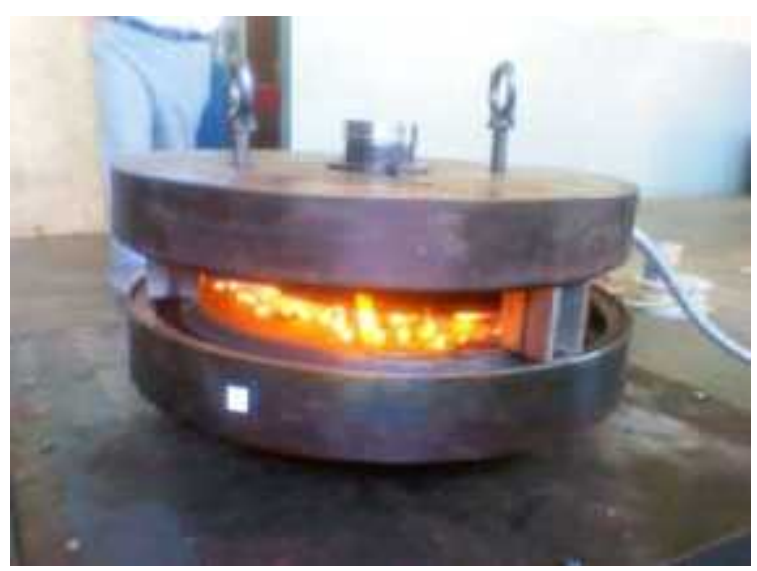

Gambar 1.Alat Centrifugal Casting. (Bambang, U, 2010)

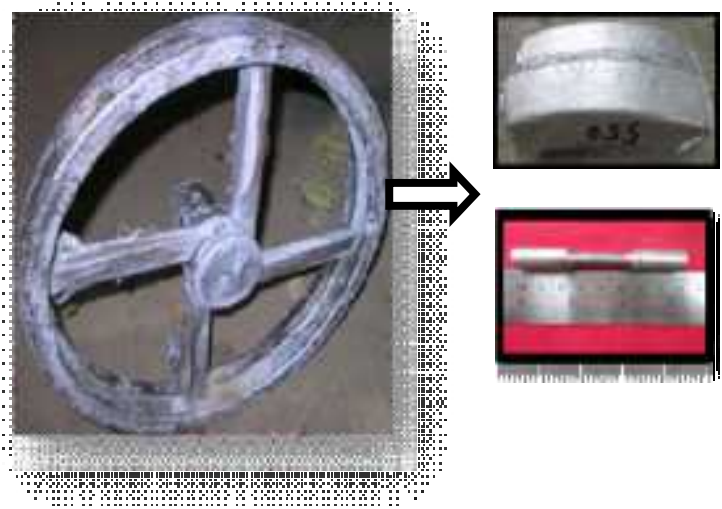

Gambar 2. Bagian Velg yang Dijadikan Benda Uji Rotary Bending. 


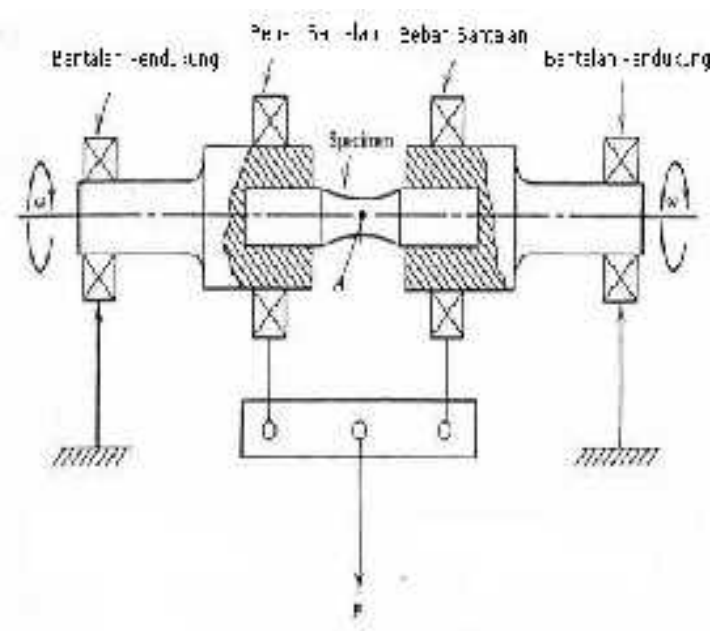

Gambar 3. Alat Uji Rotary Bending Siklus Beban Amplitudo Konstan dan Beban Lebih (Collins, 1981).

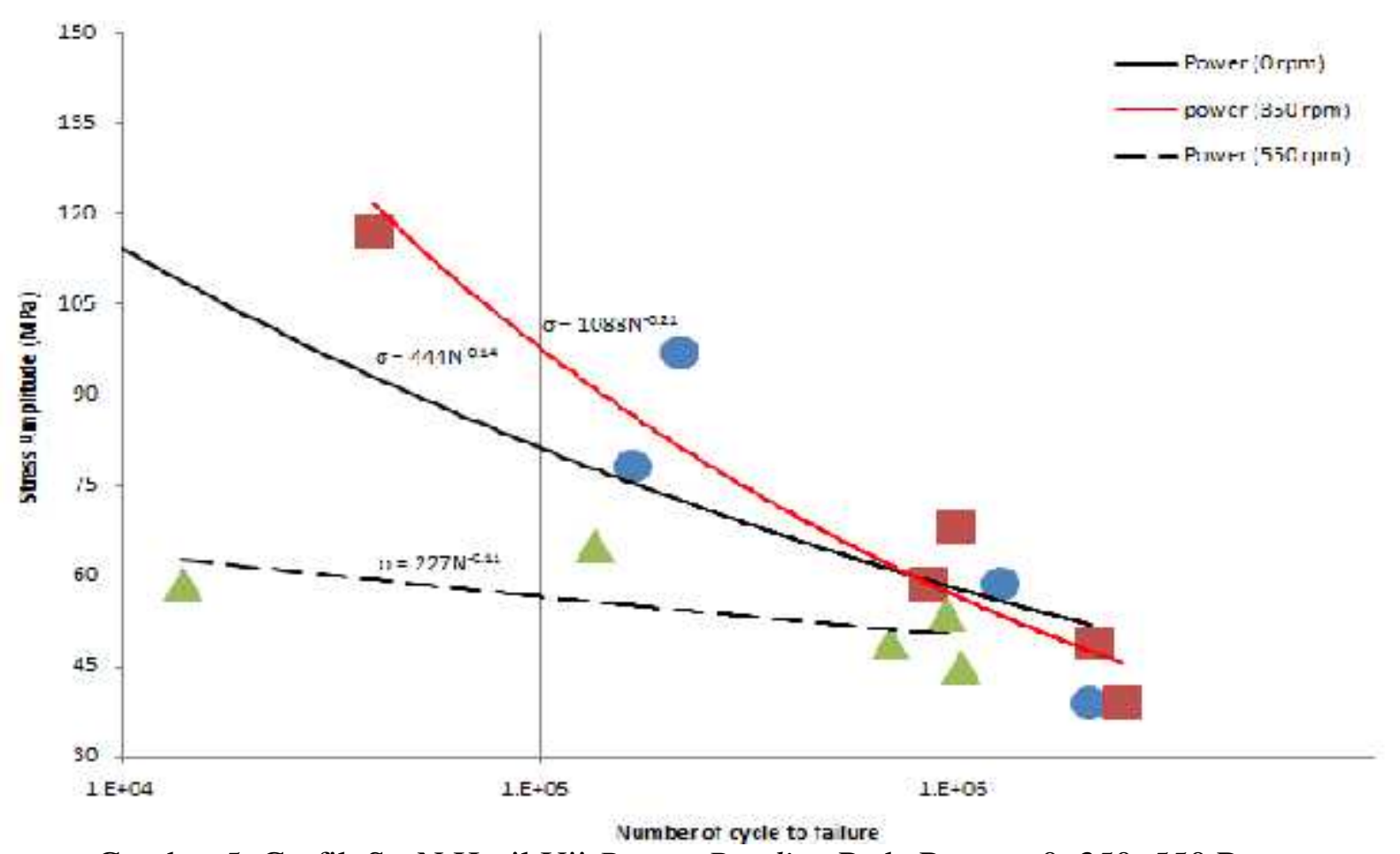

Gambar 5. Grafik S - N Hasil Uji Rotary Bending Pada Putaran 0, 350, 550 Rpm.

Dapat diketahui hasil uji rotary bending dari grafik S-N diatas, menunjukkan bahwa : Pengujian yang telah dilakukan adalah Rotary Bending Fatigue Test. Hasil pengujian menunjukkan bahwa velg dengan putaran 0 RPM menghasilkan hubungan amplitudo tegangan dengan jumlah siklus $\sigma_{a}$ $=444 \mathrm{~N}^{-0.14}$, putaran $350 \mathrm{RPM}$ mempunyai hubungan amplitudo tegangan dengan jumlah siklus $\sigma_{\mathrm{a}}=1088 \mathrm{~N}^{-0 / 21}$ dan pada putaran 550 RPM mendapatkan hubungan

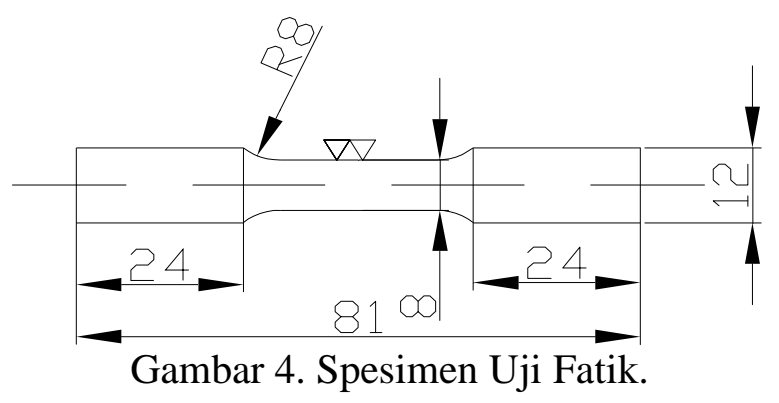

\section{HASIL DAN PEMBAHASAN}

Kekuatan lelah velg sepeda motor bahan Aluminium A.356 dengan variasi putaran mulai dari $0 \mathrm{rpm}, 350 \mathrm{rpm}$, dan $550 \mathrm{rpm}$ dapat diperoleh melalui uji kelelahan (rotari bending fatigue test)dan menganalisa grafik S-N seperti tersaji pada gambar 5 dibawah ini. 


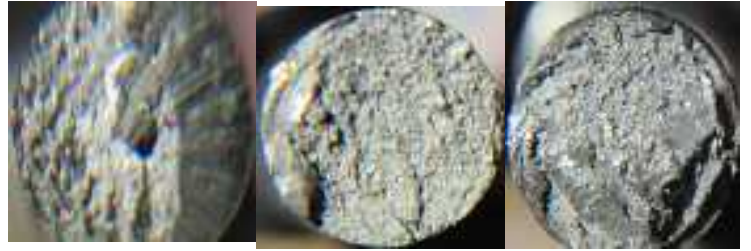

a) $0 \mathrm{rpm}$

b) $350 \mathrm{rpm}$

c) $550 \mathrm{rpm}$

Gambar 6. Permukaan Perpatahan Spesimen.

Dapat dilihat pada perpatahan benda uji pada pengujian dengan pembebanan $30 \%$ dari UTS ditunjukkan pada gambar diatas kemudian dilakukan pengamatan struktur makronya menunjukkan bahwa terjadi crack awal dan terus berkembang hingga menuju daerah penampang kemudian yang tersisa tidak kuat lagi menahan beban maka terjadi patahan akhir (final failure)yang sering disebut lelah (fatigue) akibat pembebanan yang beulang secara terus - menerus (beban dinamis).

\section{KESIMPULAN}

Hasil pengujian rotary bending pada spesimen velg sepeda motor dengan bahan A.356 dapat diambil beberapa kesimpulan sebagai berikut : Spesimen patahan permukaan 0 rpm menunjukkan pola patahan radial dimana pola ini menggambarkan spesimen yang tidak rata dan memiliki pola radial yang perpatahan terjadi di tengah (gambar a). Sedang pada spesimen benda uji $350 \mathrm{rpm}$ (gambar b) menunjukkan pola patahan yang merata secara linear dengan membuat garis pantai semakin rapat dan halus, sedang pada patahan spesimen $550 \mathrm{rpm}$ (gambar c) dengan permukaan / pola patahan yang kasar, peristiwa ini terjadi disebabkan karena getaran berlebih pada mesin uji akibat beban yang diberikan terlalu kecil, maka untuk dapat meredam geratan yang disebabkan oleh mesin diperlukan beban yang cukup seimbang dengan motor penggerak mesin rotary bending.

\section{DAFTAR PUSTAKA}

Apelian, D, Aluminium Cast Alloys : Enabling Tools for Improved performance, NADCA. 2009 : $2008: 2007: 2006: 2005$, North American Die Casting Association, 1-4 Nov 1999, Cleveland, .USA, 2009.

ASM Handbook, Intriduction to Aluminium, 2000.

ASM, Handbook, Volume 15 Casting, ASM International, 1997.

Bambang, U, Pengaruh Kecepatan Putar terhadap Sifat Fisis Mekanis pada Centrifugal Casting Aluminium Alloy Velg Sepeda Motor", Master Tesis, Indonesia, 2010.

Bintoro, W.M, Pengaruh Temperatur Cetakan, Bentuk produk dan Inokulan Ti-B Pada Proses Pengecoran Sentrifugal Terhadap Sifat Fisis dan Mekanis Paduan Aluminium. Master Tesis,UGM, Yogaykarta, 2010.

Brown, J.R, Foseco Non-Feerrous Foundryman's Handbook, 11th edition, Butterworth Heinemann, 1994.

Chirita, G., Soares, D., and Silva, F.S, Advantages of the Centrifugal Casting Technique for The Production of Structural Component with Al-Si Alloys. Master Tesis School of Enginering Minho Portugal, 2008

Joshi. A.M, Centrifugal Casting, Master Tesis, Dept. Of Metallurgical Engg. \& Material Science, Indian Institute of TechnologyBombay, India, 2010.

Makunda, P.G., Rao A.S., and Rao, S.S, "Influence of Rotation and Speed of Centrifugal Casting process on Appereance, Mikristructure and Sliding wear Behavior of Al-25 Cast Alloys". CEGC, Anna University Chennai, 2010. 
Maliwemu, Kondi,. E.U, Iswanto, T.P, Karakteristik Perambatan Retak Fatik Aluminium Scrap Dengan Variasi Putaran Centrifugal Casting, Journal Foundary Vol. 2, 2012.

Syukron, M, Karakteristik Perambatan Retak Velg dari Bahan A356 Dengan Variasi Putaran Centrifugal Casting dan Heat Treatment T6, Tesis, Universitas Gadjah Mada, 2011.

Tjitro,S.,dan Sugiharto, “Pengaruh Kecepatan Putar pada Proses Pengecoran Aluminium Centrifugal", 2004.

Vassiliou, A.N., Pantelis, D.I., and Vosniakos, G.C, "Investigation of Centrifugal Casting Conditions Influence on Part Quality”, 2008. 